\title{
Crystallographic and Magnetic Properties of $\mathrm{Li}_{0.7} \mathrm{Co}_{0.2} \mathrm{Ti}_{0.2} \mathrm{~V}_{0.2} \mathrm{Fe}_{1.7} \mathrm{O}_{4}$ Ferrite
}

\author{
Kwang Pyo Chae*, Woo Hyun Kwon, and Jae-Gwang Lee \\ Department of Applied Physics, Konkuk University, Chungju, Chungbuk 380-70, Korea
}

(Received 17 November 2009, Received in final form 4 February 2010, Accepted 5 February 2010)

\begin{abstract}
This study examined the crystallographic and magnetic properties of vanadium-substituted lithium cobalt titanium ferrite, $\mathrm{Li}_{0.7} \mathrm{Co}_{0.2} \mathrm{Ti}_{0.2} \mathrm{~V}_{0.2} \mathrm{Fe}_{1.7} \mathrm{O}_{4}$. Ferrite was synthesized using a conventional ceramic method. The samples annealed below $1040^{\circ} \mathrm{C}$ showed $\mathrm{X}$-ray diffraction peaks for spinel and other phases. However, the sample annealed above $1040^{\circ} \mathrm{C}$ showed a single spinel phase. The lattice constant of the sample was $8.351 \AA$, which was relatively unaffected by vanadium-substitution. The average grain size after vanadium- substitution was 13.90 $\mu \mathrm{m}$, as determined by scanning electron microscopy. The Mössbauer spectrum could be fitted to two Zeeman sextets, which is the typical spinel ferrite spectra of $\mathrm{Fe}^{3+}$ with $\mathrm{A}$ and $\mathrm{B}$ sites, and one doublet. From the absorption area ratio of the Mössbauer spectrum, the cation distribution was found to be $\left(\mathrm{Co}_{0.2} \mathrm{~V}_{0.2} \mathrm{Fe}_{0.6}\right)\left[\mathrm{Li}_{0.7} \mathbf{T i}_{0.2} \mathrm{Fe}_{1.1}\right] \mathrm{O}_{4}$. Vibrating sample magnetometry revealed a saturation magnetization and coercivity of $36.9 \mathrm{emu} / \mathrm{g}$ and $88.6 \mathrm{Oe}$, respectively, which were decreased by vanadium-substitution.
\end{abstract}

Keywords : Li-Co-Ti-V ferrite, Mössbauer spectroscopy, saturation magnetization, coercivity

\section{Introduction}

It was recently reported that vanadium has an interesting effect on the crystallographic and magnetic properties of ferrites. It was found that the grain size and porosity initially increase and then decrease with increasing vanadium concentration in $\mathrm{Li}_{0.5+\mathrm{t}} \mathrm{Co}_{0.2} \mathrm{Ti}_{0.2} \mathrm{~V}_{\mathrm{t}} \mathrm{Fe}_{2.1-2 \mathrm{t}} \mathrm{O}_{4}$ ferrite up to $\mathrm{t}=0.1$. It was also shown that the Curie temperature and saturation magnetization change with increasing vanadium concentration. Moreover, the addition of $\mathrm{V}_{2} \mathrm{O}_{5}$ to certain ferrites, such as $\mathrm{Li}$ ferrite, $\mathrm{Mn}-\mathrm{Zn}$ ferrite and $\mathrm{Ni}-\mathrm{Cu}-\mathrm{Zn}$ ferrite, allowed a decrease in sintering temperature and promoted densification and grain growth [1-4]. The crystallographic and magnetic properties of vanadiumsubstituted and doped ferrites were previously examined $[5,6]$.

Lithium ferrite shows a high Curie temperature, the squareness shape of the hysteresis loop, and high electric resistivity. In addition, its properties are quite sensitive to the type and amount of substituents, methodology of preparation, sintering temperature and atmosphere used in its preparation [7,8]. Cobalt ferrite is a well-known hard magnetic material that has been studied in detail due to its high coercivity (5.40 kOe), moderate saturation magneti-

*Corresponding author: Tel: +82-43-840-3623

Fax: +82-43-851-4169, e-mail: kpchae@kku.edu zation, remarkable chemical stability and mechanical hardness [9]. The crystallographic and magnetic properties of $\mathrm{Ti}^{4+}$ substituted cobalt ferrite powders of $\mathrm{Ti}_{0.2} \mathrm{Co}_{1.2} \mathrm{Fe}_{1.6} \mathrm{O}_{4}$ annealed at various temperatures ranging from $473 \mathrm{~K}$ to $1073 \mathrm{~K}$ were reported. The magnetic properties showed that an increase in annealing temperature led to a decrease in coercivity and an increase in the saturation magnetization [10]. $\mathrm{V}_{2} \mathrm{O}_{5}$ has a low melting point of $670^{\circ} \mathrm{C}$ and promotes sintering if present as a liquid phase on the grain boundaries. However, it evaporates during prolonged sintering, leaving the ferrite grain boundaries without a large excess of a $\mathrm{V}_{2} \mathrm{O}_{5}$-rich phase.

In this study, $\mathrm{Li}_{0.7} \mathrm{Co}_{0.2} \mathrm{Ti}_{0.2} \mathrm{~V}_{0.2} \mathrm{Fe}_{1.7} \mathrm{O}_{4}$ was synthesized at different annealing temperatures to clarify the crystallographic and magnetic properties of vanadium substituted Li-Co-Ti ferrite. The crystallographic and magnetic properties were examined by x-ray diffraction (XRD), scanning electron microscopy (SEM), Mössbauer spectroscopy and vibrating sample magnetometry (VSM).

\section{Experimental Method}

The vanadium-substituted lithium cobalt titanium ferrite powder, $\mathrm{Li}_{0.7} \mathrm{Co}_{0.2} \mathrm{Ti}_{0.2} \mathrm{~V}_{0.2} \mathrm{Fe}_{1.7} \mathrm{O}_{4}$, was prepared using a conventional ceramic method. The $\mathrm{Li}_{2} \mathrm{O}, \mathrm{CoO}, \mathrm{TiO}_{2}$, $\mathrm{Fe}_{2} \mathrm{O}_{3}$ and $\mathrm{V}_{2} \mathrm{O}_{5}$ powders used were all of $99.9 \%$ purity. After drying the powders at $120^{\circ} \mathrm{C}$ for $2 \mathrm{~h}$, the mixtures 
were pressed into pellets using a hydraulic press at 8 ton/ $\mathrm{cm}^{2}$. The pellets were then sintered in a furnace and annealed at $800^{\circ} \mathrm{C}$ for $6 \mathrm{~h}$, which was followed by a second annealing process at various temperatures for $6 \mathrm{~h}$. The samples were used in powder form for XRD, SEM, Mössbauer spectroscopy, and VSM.

The powder samples were analyzed by XRD at room temperature using $\mathrm{Cu}_{\mathrm{k} \alpha}(\lambda=1.5418 \AA)$ radiation. The surface microstructure was observed by SEM at room temperature. The Mössbauer spectra were obtained using a conventional electromechanical-type Mössbauer spectrometer with a ${ }^{57} \mathrm{Co}$ source $(10 \mathrm{mCi})$ in a rhodium matrix. The magnetic properties were measured using a VSM.

\section{Results and Discussion}

Fig. 1 shows the XRD patterns of the vanadium-substituted lithium cobalt titanium ferrite, $\mathrm{Li}_{0.7} \mathrm{Co}_{0.2} \mathrm{Ti}_{0.2} \mathrm{~V}_{0.2^{-}}$ $\mathrm{Fe}_{1.7} \mathrm{O}_{4}$, at various annealing temperature. At annealing temperatures $<1040^{\circ} \mathrm{C}$, the XRD pattern showed peaks consistent with a typical spinel structure with additional peaks, which were assigned to $\mathrm{Fe}_{2} \mathrm{O}_{3}$. However, above $1040^{\circ} \mathrm{C}$, all the XRD peaks were consistent with those of a typical spinel structure. Therefore, the samples annealed at temperatures $>1040{ }^{\circ} \mathrm{C}$ were used in this study. The

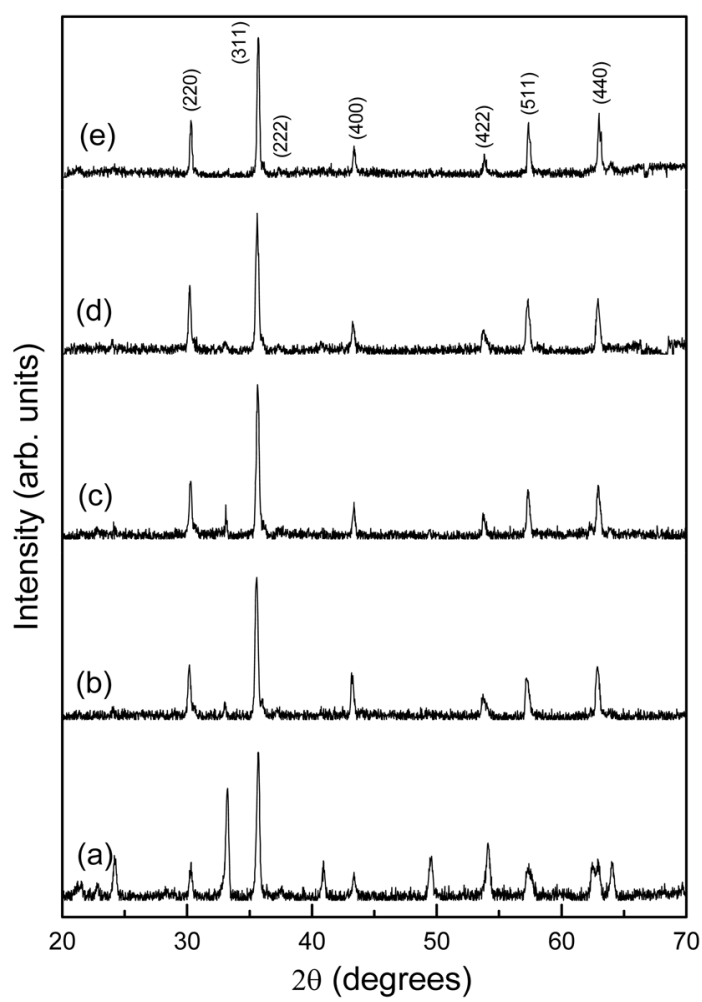

Fig. 1. X-ray diffraction patterns of $\mathrm{Li}_{0.7} \mathrm{Co}_{0.2} \mathrm{Ti}_{0.2} \mathrm{~V}_{0.2} \mathrm{Fe}_{1.7} \mathrm{O}_{4}$ ferrites annealed at (a) 700, (b) 990, (c) 1000, (d) 1020, and (e) $1040{ }^{\circ} \mathrm{C}$. lattice constant $a$, as calculated from the observed interplanar spacing $d$ value, was $8.351 \AA$, which indicates that the lattice constant is relatively unaffected by vanadium substitution (the lattice constant for non vanadium substituted ferrite, $\mathrm{Li}_{0.5} \mathrm{Co}_{0.2} \mathrm{Ti}_{0.2} \mathrm{Fe}_{2.1} \mathrm{O}_{4}$, is $8.349 \AA$ ). As reported previously [1], this was explained by the composition formula, where one $\mathrm{Fe}^{3+}$ ion $(0.67 \AA)$ is replaced with $0.5 \mathrm{Li}^{+}$and $0.5 \mathrm{~V}^{5+}$ with an average ionic radius of $0.665 \AA$ (the ionic radii of $\mathrm{Li}^{+}$and $\mathrm{V}^{5+}$ are 0.74 $\AA$ and $0.59 \AA$, respectively).

Fig. 2 shows $\mathrm{SEM}$ images of the $\mathrm{Li}_{0.7} \mathrm{Co}_{0.2} \mathrm{Ti}_{0.2} \mathrm{~V}_{0.2} \mathrm{Fe}_{1.7} \mathrm{O}_{4}$ sample at x 2000 magnification. The average grain size and/or morphology of the Li-Co-Ti ferrite was reported to be strongly dependent on the amount of vanadium present in the samples during annealing [5]. As the level of substitution increased, some larger grains were embedded in finer grains, and the number of these grains increased with increasing size. The average grain size of the $\mathrm{Li}_{0.7} \mathrm{Co}_{0.2} \mathrm{Ti}_{0.2} \mathrm{~V}_{0.2} \mathrm{Fe}_{1.7} \mathrm{O}_{4}$ sample was $13.90 \mu \mathrm{m}$, which is larger than the average grain size of non vanadium substituted $\mathrm{Li}_{0.5} \mathrm{Co}_{0.2} \mathrm{Ti}_{0.2} \mathrm{Fe}_{2.1} \mathrm{O}_{4}(3.04 \mu \mathrm{m})$.

Mössbauer spectroscopy is used to examine the microstructural properties of substituted systems, e.g. ferrites, in a way that XRD and SEM cannot. Fig. 3(a) and (b) show the Mössbauer absorption spectrum for the vana-

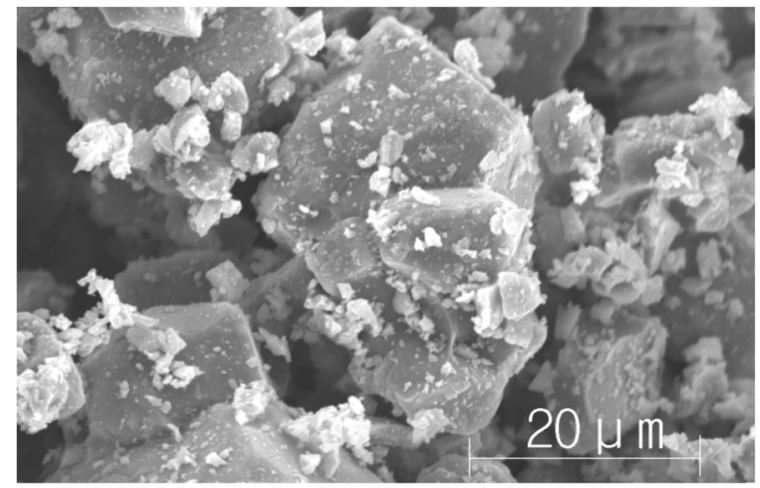

(a)

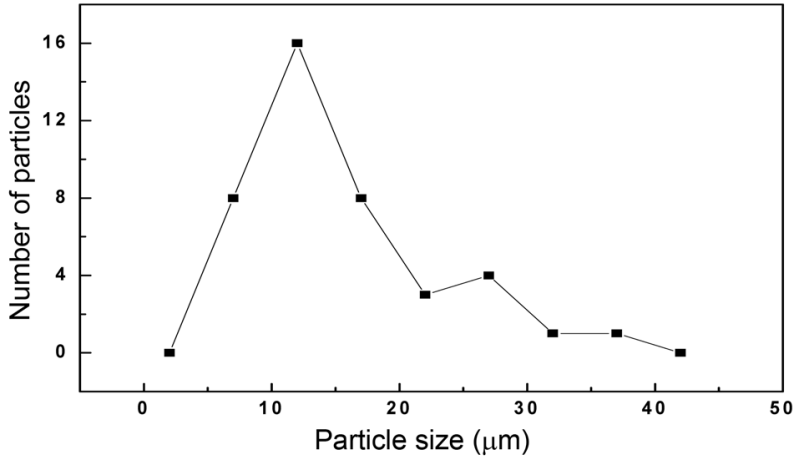

(b)

Fig. 2. (a) SEM image, and (b) grain size distribution of $\mathrm{Li}_{0.7} \mathrm{Co}_{0.2} \mathrm{Ti}_{0.2} \mathrm{~V}_{0.2} \mathrm{Fe}_{1.7} \mathrm{O}_{4}$ ferrite. 


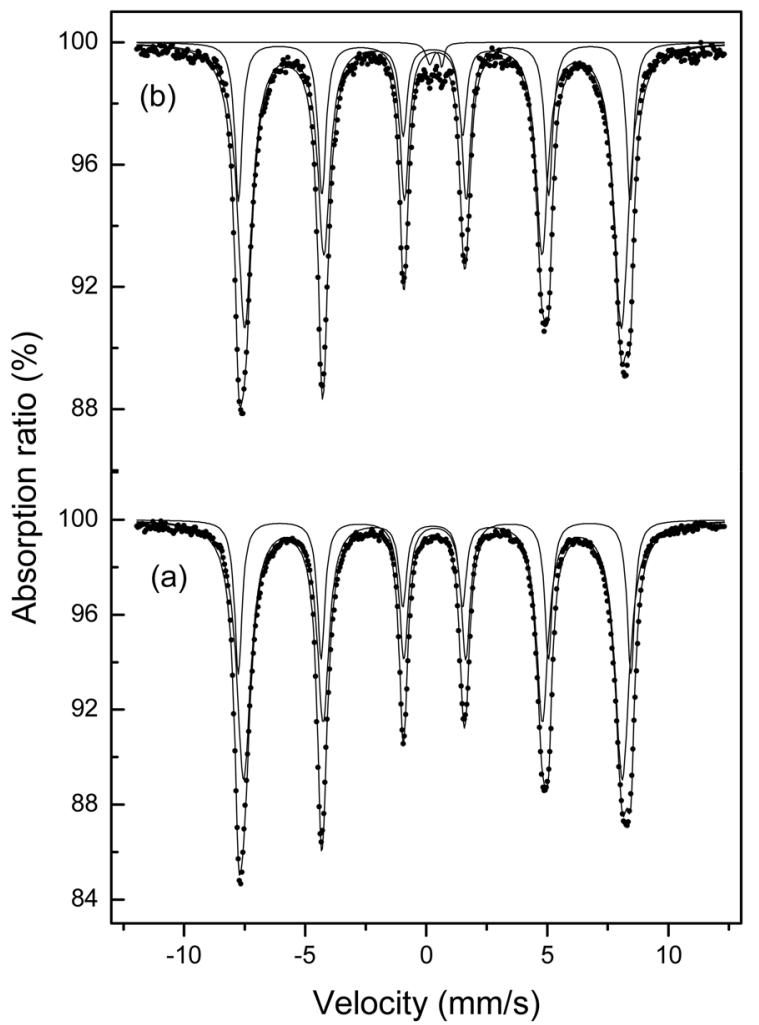

Fig. 3. Mössbauer spectrum of (a) the non vanadium ion-substituted $\mathrm{Li}_{0.5} \mathrm{Co}_{0.2} \mathrm{Ti}_{0.2} \mathrm{Fe}_{2.1} \mathrm{O}_{4}$, and (b) the vanadium ion-substituted $\mathrm{Li}_{0.7} \mathrm{Co}_{0.2} \mathrm{Ti}_{0.2} \mathrm{~V}_{0.2} \mathrm{Fe}_{1.7} \mathrm{O}_{4}$ at room temperature.

dium-nonsubstituted and substituted lithium cobalt titanium ferrites measured at room temperature. For non vanadium-substituted ferrite, $\mathrm{Li}_{0.5} \mathrm{Co}_{0.2} \mathrm{Ti}_{0.2} \mathrm{Fe}_{2.1} \mathrm{O}_{4}$, the spectrum was fitted with two sextet subspectra from the $\mathrm{Fe}^{3+}$ at the tetrahedral A and octahedral B sites of a typical spinel crystal structure. However, for the vanadium-substituted ferrite the spectrum was fitted with two sextet subspectra and one doublet. There are several causes for the appearance of a doublet in the Mössbauer spectrum of $\mathrm{Fe}^{3+}$ ions in spinel ferrites; (a) paramagnetic phase, (b) superparamagnetic state and (c) appearance of another crystal structure etc. The XRD, SEM, Mössbauer and VSM data for the samples formed at various compositions and annealing temperatures showed no other crystal phases and all samples were magnetic ordering states. Therefore, it was decided that the Fe ions, which do not participate in the superexchange process in the spinel structure, produced the doublet in the Mössbauer spectrum. In $\mathrm{Li}_{0.7} \mathrm{Co}_{0.2} \mathrm{Ti}_{0.2} \mathrm{~V}_{0.2} \mathrm{Fe}_{1.7} \mathrm{O}_{4}$, approximately $98.89 \%$ of the $\mathrm{Fe}$ ions participate in the superexchange process in this spinel structure and $1.11 \%$ do not participate in the superexchange process, as shown in Table 1. This means that $\mathrm{Fe}^{3+}$ ions that escape and/or overflow from the $\mathrm{B}$ site do not participate in the A-O-B superexchange interaction. Hence, they show quadruple splitting in the Mössbauer spectra. Some papers $[11,12]$ reported that the $\mathrm{V}_{2} \mathrm{O}_{5}$ addition yields a liquid phase in spinel ferrites that also has some $\mathrm{Fe}^{2+}$ ions and/or vacancies, but no evidence of this was found in our Mössbauer results. The effects of vanadium ion substitution in the Li-Co-Ti ferrite Mössbauer parameters were reported as follows [5]: The isomer shift (IS) values are relatively constant with substituted vanadium contents. However, the magnetic hyperfine fields $\left(H_{h f}\right)$ decreased with increasing substituted vanadium content. In particular, the rapid decrease in quadruple splitting (QS) of the A site suggests that the substitution of vanadium has a larger influence on the $\mathrm{A}$ site than on the $\mathrm{B}$ site with the electric field gradient. The doublet area of the Mössbauer spectra increases with increasing substituted vanadium content, and the areas of the A and $\mathrm{B}$ sites show some decrease with increasing vanadium concentration. This suggests that the vanadium ions mainly enter into the spinel sites, substituting for $\mathrm{Fe}$ ions.

The cation distribution can be determined using the site preference and Mössbauer spectra ratio. The cation distribution depends on a variety of factors, including the temperature, pressure, composition and preparation method. The cation distribution in lithium ferrite with vanadium substitution $(\mathrm{x}=0.5)$ was reported [13] to be $\left(\mathrm{Fe}_{0.55} \mathrm{~V}_{0.45}\right)$ $\left[\mathrm{Fe}_{0.95} \mathrm{LiV}_{0.05}\right] \mathrm{O}_{4}$. Using the lithium and titanium ions located in the $\mathrm{B}$ site and vanadium ions and cobalt ions that enter into the A site, it was determined that the cation distribution of the sample was

Table 1. Room temperature Mössbauer parameters of (a) non vanadium substituted lithium cobalt titanium ferrite, $\mathrm{Li}_{0.5} \mathrm{Co}_{0.2} \mathrm{Ti}_{0.2} \mathrm{Fe}_{2.1} \mathrm{O}_{4}$ and (b) vanadium substituted lithium cobalt titanium ferrite, $\mathrm{Li}_{0.7} \mathrm{Co}_{0.2} \mathrm{Ti}_{0.2} \mathrm{~V}_{0.2} \mathrm{Fe}_{1.7} \mathrm{O}_{4}$. $H_{\text {hf }}$ is the magnetic hyperfine field, $Q S$ is the quadrupole splitting, and $I S$ is the isomer shift relative to the metallic iron. The area ratio (A/B) and doublet represent the Mössbauer spectra absorption area ratio of the A and B sites, and doublet.

\begin{tabular}{|c|c|c|c|c|c|c|c|c|}
\hline & \multirow{2}{*}{ spectrum } & \multicolumn{2}{|c|}{$H_{h f}(\mathrm{kOe})$} & \multicolumn{2}{|c|}{$Q S(\mathrm{~mm} / \mathrm{s})$} & \multicolumn{2}{|c|}{$I S(\mathrm{~mm} / \mathrm{s})$} & \multirow{2}{*}{$\begin{array}{c}\text { Area ratio } \\
\text { (A/B, doublet) }\end{array}$} \\
\hline & & A site & B site & A site & B site & A site & B site & \\
\hline (a) & sextet & 502.6 & 484.7 & -0.004 & 0.005 & 0.349 & 0.273 & $33.7 / 66.3$ \\
\hline \multirow{2}{*}{ (b) } & sextet & 501.4 & 482.2 & -0.219 & 0.002 & 0.354 & 0.280 & $33.5 / 65.4$ \\
\hline & doublet & \multicolumn{2}{|c|}{ - } & \multicolumn{2}{|c|}{0.500} & \multicolumn{2}{|c|}{0.396} & 1.11 \\
\hline
\end{tabular}




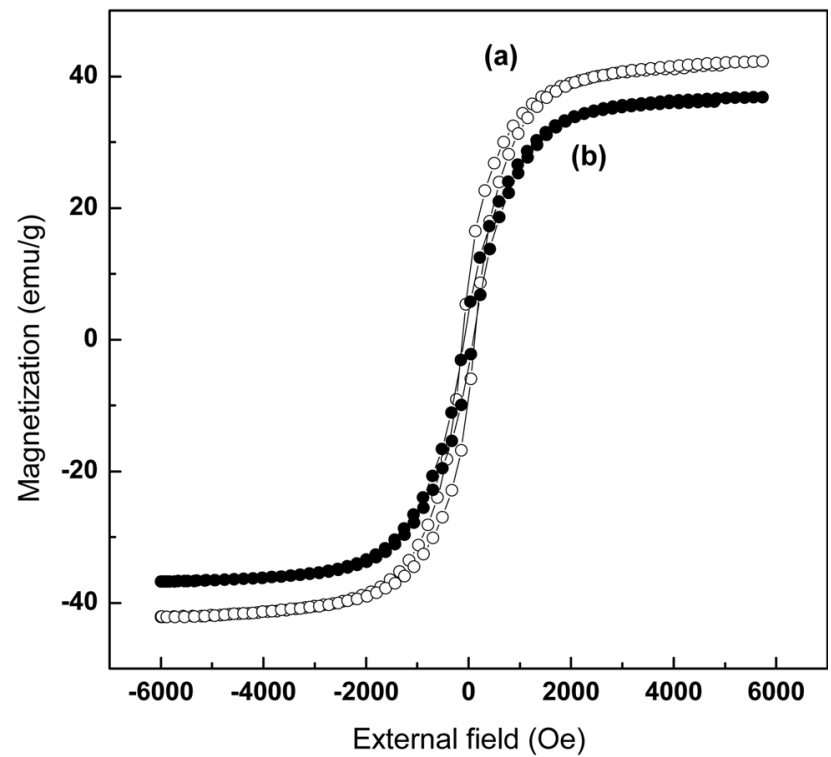

Fig. 4. Hysteresis curve of (a) the non vanadium ion-substituted $\mathrm{Li}_{0.5} \mathrm{Co}_{0.2} \mathrm{Ti}_{0.2} \mathrm{Fe}_{2.1} \mathrm{O}_{4}$, and (b) the vanadium ion-substituted $\mathrm{Li}_{0.7} \mathrm{Co}_{0.2} \mathrm{Ti}_{0.2} \mathrm{~V}_{0.2} \mathrm{Fe}_{1.7} \mathrm{O}_{4}$ ferrite.

$$
\left(\mathrm{Co}_{0.2} \mathrm{~V}_{0.2} \mathrm{Fe}_{0.6}\right)\left[\mathrm{Li}_{0.7} \mathrm{Ti}_{0.2} \mathrm{Fe}_{1.1}\right] \mathrm{O}_{4} \text {, }
$$

where a small amount of vanadium and cobalt can go into the $\mathrm{B}$ site.

The magnetic properties of the samples were determined at room temperature using a vibrating sample magnetometer. Fig. 4 shows the hysteresis curve of (a) the non vanadium ions substituted $\mathrm{Li}_{0.5} \mathrm{Co}_{0.2} \mathrm{Ti}_{0.2} \mathrm{Fe}_{2.1} \mathrm{O}_{4}$, and (b) the vanadium ions substituted $\mathrm{Li}_{0.7} \mathrm{Co}_{0.2} \mathrm{Ti}_{0.2} \mathrm{~V}_{0.2} \mathrm{Fe}_{1.7} \mathrm{O}_{4}$. The saturation magnetization $\left(M_{S}\right)$ of the vanadium ions substituted $\mathrm{Li}_{0.7} \mathrm{Co}_{0.2} \mathrm{Ti}_{0.2} \mathrm{~V}_{0.2} \mathrm{Fe}_{1.7} \mathrm{O}_{4}$ was $36.9 \mathrm{emu} / \mathrm{g}$, and the coercivity $\left(H_{C}\right)$ was 88.6 Oe. The lower saturation magnetization of the sample compared to that of the non vanadium ion-substituted ferrites (for $\mathrm{Li}_{0.5} \mathrm{Co}_{0.2} \mathrm{Ti}_{0.2} \mathrm{Fe}_{2.1} \mathrm{O}_{4}$, the $M_{S}$ is $41.6 \mathrm{emu} / \mathrm{g}$ ) can be understood based on the nonmagnetic vanadium and lithium ion substitution. Because the coercivity is inversely proportional to the grain size [1], the lower coercivity of the sample than that of the non vanadium ion-substituted ferrites (for $\mathrm{Li}_{0.5^{-}}$ $\mathrm{Co}_{0.2} \mathrm{Ti}_{0.2} \mathrm{Fe}_{2.1} \mathrm{O}_{4}$, the $H_{C}$ is $120.4 \mathrm{Oe}$ ) can be understood based on the large grain size.

\section{Conclusion}

The crystallographic and magnetic properties of vanadium-substituted lithium cobalt titanium ferrite, $\mathrm{Li}_{0.7} \mathrm{Co}_{0.2}-$ $\mathrm{Ti}_{0.2} \mathrm{~V}_{0.2} \mathrm{Fe}_{1.7} \mathrm{O}_{4}$, were investigated. Ferrite was synthesized using a conventional ceramic method. The samples show- ed a single phase with a spinel structure at annealing temperatures $>1040^{\circ} \mathrm{C}$ with a lattice parameter of 8.351 $\AA$. The lattice parameter was relatively unaffected by vanadium substitution. The average grain size of the sample increased to $13.90 \mu \mathrm{m}$ due to vanadium substitution. The Mössbauer spectra could be fitted with two Zeeman sextets, which is the typical spinel ferrite spectra of $\mathrm{Fe}^{3+}$ with $\mathrm{A}$ and $\mathrm{B}$ sites, and one doublet. From the absorption area ratio of the Mössbauer spectrum, the cation distribution was determined to be $\left(\mathrm{Co}_{0.2} \mathrm{~V}_{0.2} \mathrm{Fe}_{0.6}\right)$ $\left[\mathrm{Li}_{0.7} \mathrm{Ti}_{0.2} \mathrm{Fe}_{1.1}\right] \mathrm{O}_{4}$. The saturation magnetization and coercivity was $36.9 \mathrm{emu} / \mathrm{g}$ and $88.6 \mathrm{Oe}$, respectively, which were reduced by vanadium substitution.

\section{Acknowledgements}

This study was supported by Konkuk University in 2009.

\section{References}

[1] M. Maisnam, S. Phanjoubam, H. N. K. Sarma, L. R. Devi, O. P. Thakur, and C. Prakash, Physica B 352, 86 (2004).

[2] M. Maisnam, S. Phanjoubam, H. N. K. Sarma, C. Prakash, L. R. Devi, and O. P. Thakur, Materials Letter 58, 2412 (2004).

[3] L. M. Letyuk, Poroshk, Metall. 8, 59 (1975).

[4] T. S. Kwon, S. S. Kim, and D. H. Kim, Colloque C1, Suppl. J. Phys. Mars III 231 (1997).

[5] W. H. Kwon, S. H. Lee, J. G. Lee, and K. P. Chae, J. Magn. Magn. Mater. (submitted 2009).

[6] W. H. Kwon, S. H. Lee, J. G. Lee, and K. P. Chae, J. Kor. Phys. Soc. 55, 1548 (2009).

[7] S. Phanjoubam, D. Kothari, and J. S. Baijal, Phys. Status Solidi A 111, 131 (1989).

[8] P. D. Baba, G. M. Argentina, W. E. Courtney, G. F. Dionne, and D. H. Dionne, IEEE Trans. Magn. 8, 83 (1972).

[9] Y. Suzuki, G. Hu, R. B van Dover, and R. J. Cava. J. Magn. Magn. Mater. 191, 1 (1999).

[10] K. P. Chae, W. K. Kim, J. G. Lee, and Y. B. Lee, Hyperfine Interactions 136, 65 (2001).

[11] V. Nivoix and B. Gillot, Mater. Chem. Phys. 63, 24 (2000).

[12] M. Nohair, D. Aymes, P. Perriat, and B. Gillot, Vibrational Spect. 9, 181 (1995).

[13] S. V. Salvi and V. P. Khanolkar, Proceddings, $5^{\text {th }}$ Int. Conf. Ferrites, Bombay, India (1989) pp.459. 